\title{
PENGELOLAAN KEUANGAN BERBASIS SAK EMKM PADA PENGUSAHA KULINER KELURAHAN WONODRI SEMARANG
}

\author{
David Firna Setiawan *1, Novika Wahyuhastuti ${ }^{2}$, Aryan Eka Prastya Nugraha ${ }^{3}$, Inayah Adi Sari ${ }^{4}$ \\ 1,2,3,4 Universitas PGRI Semarang \\ ${ }^{3}$ Pendidikan Ekonomi, FPIPSKR, Universitas PGRI Semarang \\ *e-mail: davidfirnasetiawan@gmail.com ${ }^{1}$,novikawidodo@gmail.com² ${ }^{2}$ aryaneka@upgris.ac.id ${ }^{3}$ \\ inayahadisari@gmail.com
}

\begin{abstract}
The purpose of this Community Partnership Program is to provide solutions to problems faced by partners, namely problems in business management and marketing of SME products in Wonodri Village and developing culinary businesses into businesses with quality products and competitive in the market with effective business financial management. This PKM activity will be carried out in Wonodri Village, South Semarang District, Semarang City.

The solution offered by the proposer to partners related to the production problems faced is to provide education on how to make products so that more varied food products are produced. The continuous process of the production process is the product marketing process. In the management aspect, the implementation method is given by providing training in bookkeeping in managing business finances. In this stage, partners will receive training and assistance by experts in preparing working capital, to carrying out bookkeeping related to income and expenses. The results show that there is an increase in the ability of partners regarding the simple bookkeeping process.
\end{abstract}

Keywords: business financial management, strengthening economic activity, culinary

\section{Abstrak}

Tujuan Program Kemitraan Masyrakat ini adalah untuk memberikan solusi terhadap permasalahan yang dihadapi mitra, yaitu permasalahan manajemen pengelolaan usaha dan pemasaran produk UKM Kelurahan Wonodri serta mengembangkan usaha kuliner menjadi usaha dengan produk yang berkualitas dan berdaya saing di pasar dengan pengelolaan keuangan bisnis yang efektif. Kegiatan PKM ini akan dilaksanakan di Kelurahan Wonodri Kecamatan Semarang Selatan Kota Semarang.

Solusi yang ditawarkan pengusul kepada mitra terkait dengan permasalahan produksi yang dihadapi adalah memberikan edukasi cara membuat produk sehingga dihasilkan produk pangan yang lebih variative. Proses yang berkelanjutan dari proses produksi adalah proses pemasaran produk Pada aspek manajemen, metode pelaksanaan yang diberikan dengan memberikan pelatihan penyusunan pembukuan dalam mengelola keuangan bisnis. Dalam tahap ini mitra akan mendapatkan pelatihan serta pendampingan oleh pakar dalam menyusun modal kerja, sampai melakukan pembukuan terkait dengan pendapatan dan biaya. Hasil diketahui bahwa ada peningkatan pada kemampuan mitra mengenai proses pembukuan sederhana.

Kata kunci: pengelolaan keuangan bisnis, penguatan kegiatan perekonomian, kuliner

\section{PENDAHULUAN}

Kegiatan PKM ini didasari dari hasil survei mengenai kondisi masyarakat usaha kuliner Kelurahan Wonodri, yang menghasilkan bahwa para pelaku usaha kuliner belum mempunyai teori dasar ilmu mengenai produk, teori dan aplikasi pemasaran yang masih sederhana dan belum mengadakan pembukuan secara baik. Dari hasil observasi, permasalahan yang dihadapi mitra di Kelurahan Wonodri dan akan diperpaiki dalam program Kemitraan Masyarakat ini adalah permasalahan bidang produksi, pemasaran dan bidang manajemen. 
Kegiatan Program Kemitraan Masyarakat ini akan dilakukan di Kelurahan Wonodri, dengan sasaran masyarakat yang produktif secara ekonomi, namun kurang bisa berkembang. Mitra adalah pengusaha kuliner. Permasalahan yang dihadapi mitra adalah terkait dengan aspek produksi adalah kualitas produk yang kurang bagus, sehingga kurang diminati konsumen. Hal ini menyebabkan produk kurang diminati dan tidak berdaya saing di pasar, mengingat kompetitor yang semakin banyak. Selain permasalahan tersebut, proses pemasaran yang dilakukan masih tradisional. Barang dagangan hanya di pajang di toko yang sekaligus rumah tinggal mitra atau disetorkan ke pasar yang terdekat. Mitra belum mengenal perdagangan melalui e-commerce, sehingga pemasaran produk hanya sekitar lokasi usaha. Kegiatan pengabdian masyarakat akan mengarahkan pada pemberian manfaat langsung maupun tidak langsung yang melibatkan pribadi, institusi, pemerintah, swasta dan pihak-pihak yang memiliki kepedulian pada peningkatan kesejahteraan masyarakat individu (Efriyenty, 2021).

Salah satu bidang usaha yang berkembang dan konsisten pada perekonomian di Indonesia yaitu kegiatan UMKM. Sehingga, pelaku UMKM harus selalu meningkatkan kapasitas dan kualitas agar dapat bersaing secara global (Hidayatulloh \& Maulana, 2021). Laporan keuangan juga digunakan untuk melakukan analisis untuk membuat keputusan dan dapat digunakan untuk pertanggungjawaban kegiatan usaha (Luchindawati, Nuraina, \& Astuti, 2021). Permasalahan yang dihadapi mitra terkait dengan aspek manajemen keuangan adalah mitra belum mengenal cara pengelolaan keuangan bisnis dengan benar. Keuangan bisnis mengalir begitu saja, yang pada akhirnya modal mereka habis tanpa terasa. Karena mitra tidak mengadakan pembukuan dengan baik, maka nota-nota transaksi penjualan produk dan pembelian bahan baku terbuang begitu saja. Hal ini menyebabkan tidak diketahuinya secara pasti keuntungan yang diperoleh mitra, sehingga modal mereka terkikis habis tanpa disadari. Maka dari itu diperlukan sebuah solusi untuk menyelesaikan permasalahan yang dihadapi mitra, baik permasalahan dari aspek produksi maupun aspek manajemen. Mengingat usaha kuliner ini sangat berpotensi untuk berkembang menjadi usaha dengan skala yang lebih besar. Tidak hanya soal pemasaran kesiapan pengelolaan 'rumah tangga' industri juga harus dipersiapkan sebaik mungkin, diantaranya kesiapan pengelolaan bisnis, pengelolaan keuangan usaha, pengelolaan stok barang sampai pada pengelolaan pelayanan konsumen(Ardaninggar, Rudy, Sumantri, \& Nugroho, 2020).

Proses untuk mencatat dan menyajikan informasi dan kondisi keuangan yang digunakan untuk membuat keputusan (Purnomo \& Adyaksana, 2021). Manajemen keuangan wirausaha harus lebih simple, sederhana dan aplikatif, namun tetap dalam ketentuan yang standard dan lazim. Untuk itu perlu mempertimbangkan karakternya yang memiliki kecepatan perputaran dan jenis usaha yang relatif sederhana (baik dalam skala usaha maupun SDMnya). UMKM juga diwajibkan membuat Laporan Keuangan yang baik agar setiap transaksi dalam kegiatan usaha dicatat dan disusun sesuai aturan yang lazim. Penyusunannya dalam bentuk catatan akuntansi sederhana melalui proses akuntansi yan dimulai dari identifikasi data sampai dengan analisis Laporan Keuangan. Laporan keuangan adalah suatu penyajian terstruktur dari posisi keuangan dan kinerja keuangan suatu entitas (Jaurino, 2021). Tujuan laporan keuangan adalah menyediakan informasi yang menyangkut posisi keuangan, kinerja, serta perubahan posisi keuangan suatu perusahaan yang bermanfaat bagi sejumlah besar pemakai dalam pengambilan keputusan (Suwondo, 2021). Menurut SAK EMKM Tahun 2016,komponen Laporan keuangan untuk entitas, mikro, kecil, dan menengah terdiri dari : Laporan Posisi Keuangan, Laporan Laba Rugi, dan Catatan atas Laporan Keuangan (Wibowo, Putri, \& Nasution, 2020). Standar Akuntansi untuk Entitas Mikro,Kecil dan Menengah (SAK EMKM) tersebut berlaku efektif per 1 Januari 2018 namun penerapan sebelum tanggal efektif 
diperbolehkan. Standar ini dikemas cukup ringkas jika dibandingkan dengan Standar Akuntansi Keuangan (SAK) ETAP (Purwati, Suparlinah, \& Putri, 2018).

Terdapat beberapa kekhususan standar dalam SAK EMKM, beberapa diantaranya adalah komponen laporan keuangan EMKM hanya terdiri dari neraca, laporan laba rugi dan catatan atas laporan keuangan, dasar pengukuran unsur-unsur laporan keuangan hanya dengan basis biaya historis (Kirowati \& Amir, 2019).

Solusi yang diberikan kepada mitra diharapkan dapat membantu mitra dalam mengembangkan usahanya, khususnya terkait dengan produksi yang berkualitas, pemasaran produk dengan e-commerce sehingga produk mudah dikenal di masyarakat, dan pengelolaan keuangan bisnis yang sehat. Target yang direncanakan tersebut diharapkan dapat dicapai pada tahap implementasi dan evaluasi. Tujuan akhir dari Program Kemitraan Masyarakat ini adalah berkembangnya usaha kuliner yang sudah ada menjadi usaha kuliner dengan produk yang berkualitas, sehingga dapat bersaing di pasar dan pengelolaan keuangan bisnis yang sehat, sehingga dapat menjadi suber pendapatan penduduk Kelurahan Wonodri.

\section{METODE}

Tujuan dari Program Kemitraan Masyarakat ini adalah meningkatkan pendapatan mitra melalui perbaikan kualitas dan variasi produk, pemasaran dengan e-commerce, dan pengelolaan keuangan bisnis yang efektif. Metode pelaksanaan kegiatan program pengabdian masyarakat ini terkait dengan permasalahan aspek produksi dan aspek manajemen adalah sebagai berikut: Metode Pelaksanaan dari Aspek Produksi dan Pemasaran Metode yang digunakan dalam rangka menjawab permasalahan manajemen yang dihadapi mitra adalah:

a. Melakukan pelatihan dan praktik pembuatan toko online Berupa pelatihan dan pendampingan pembuatan toko online pada situs jual beli online yang terpercaya. Pelatihan dilakukan langsung dengan praktik dan secara intensif terus didampingi oleh pakar Teknologi Informasi.

b. Melakukan pelatihan pemotretan produk untuk diunggah di toko online. Sebagai salah satu nilai produk ketika dipasarkan melalui media online, maka tampilan produk menjadi perhatian utama bagi pembeli. Maka akan dilakukan pelatihan dan pendampingan intensif tentang cara memotret produk dengan pilihan angel yang bagus serta cara posting di laman toko online yang telah dibuat.

c. Melakukan pelatihan pengepakan kemasan. Pengepakan merupakan bagian dari pelayanan e-commerce. Untuk itu dibutuhkan keahlian khusus agar proses pengiriman barang dapat dilakukan dengan tanpa mengubah kondisi barang mengingat barang yang dijual adalah produk kuliner yang rentan dengan kerusakan, sehingga mengurangi keindahan produk.

d. Melakukan praktik pengiriman barang. Setelah pengepakan mitra akan diperkenalkan dengan jasa pengiriamn yang memungkinkan bagi produk dan berlokasi dekat dengan mitra. Mitra akan didampingi melakukan perjanjian dengan perusahaan jasa pengiriman agar mendapatkan prioritas pelayananan maupun biaya pengiriman. 
e. Melakukan pelatihan pengelolaan usaha. Sebagai usaha dengan orientasi profit, maka mitra perlu diberikan pelatihan mengenai pengelolaan keuangan suatu usaha agar UMKM yang dibentuk dapat terus berkembang dan berkelanjutan, dalam arti dapat menjadi usaha yang menguntungkan dari sisi bisnis.

f. Melakukan pendampingan mencari permodalan usaha. Modal merupakan suatu hal yang penting pada setiap usaha. Dan modal pula merupakan salah satu permasalahan yang dihadapi mitra. Tim pengusul akan melakukan pendampingan dengan membantu mencarikan pihak pemberi modal seperti bank, koperasi, bantuan pemerintah, dan lain-lain sebagai pihak yang memberikan bantuan modal dengan syarat yang ringan bagi mitra.

\section{HASIL DAN PEMBAHASAN}

Kegiatan pengabdian kepada masyarakat ini dilaksanakan dalam 3 tahap, yaitu bidang kewirausahaan, bidang pengelolaan keuangan, dan bidang pemasaran. Penyampaian materi disesuaikan dengan keahlian masing-masing. Peserta kegiatan ini adalah para pelaku usaha mikro dan kecil dalam bidang kuliner. Kegiatan ini dilaksanakan pada hari Rabu, tanggal 3 Januari 2020, bertempat di rumah Ketua RW 05 Kelurahan Wonodri Kota Semarang. Kegiatan ini dihadiri sekitar 20 orang.

Kegiatan PKM ini terinspirasi dari permasalahan yang dihadapi mitra, yaitu masalah pengelolaan keuangan bisnis dan strategi pemasaran yang tepat. Pada pertemuan ini tim PKM memberikan solusi terkait dengan permasalahan yang dihadapi mitra dalam bentuk sosialisai dan penyuluhan serta tanya jawab mengenai permasalahan yang mereka hadapi. Para peserta kegiatan PKM ini sangat antusias dalam mengikuti acara. Hal ini ditunjukkan dengan banyaknya julah peserta yang hadir dan kesungguhan dalam mengikuti rangkaian acara dari awal sampai akhir. Dari Kegiatan PKM ini ditemukan permasalahan lebih lanjut yang dihadapi mitara, yaitu bagaimana menyusun laporan keuangan bisnis sebagai penyedia informasi yang berguna untuk pengembangan bisnis.

Luaran kegiatan PKM ini adalah pemberian modul kepada peserta, yaitu anggota kelompok usaha mikro dan kecil bidang kuliner. Modul yang diberikan antara lain:

a. Modul Kewirausahaan. Modul ini berisi materi-materi mengenai bagaimana berwirausaha yang mempunyai pangsa pasar yang bagus. Selain itu, modul ini juga memberikan wawasan bagi para pelaku bisnis untuk bisa menciptakan usaha bisnis yang unggul.

b. Modul Pengelolaan Keuangan Bisnis. Modul ini berisi bagaimana mengelola keuangan yang bermula dari unit terkecil, yaitu rumah tangga sampai keuangan unit usaha. Pengelolaan keuangan yang diharapkan bisa menciptakan keuangan yang sehat dan akuntabel.

c. Modul Pemasaran. Modul ini memberikan pengetahuan mengenai bagaimana strategi pemasaran yang efektif sehingga bisa memenangkan persaingan usaha. Dengan mempelajari modul ini, diharapkan para pelaku usaha bisa menemukan strategi untuk memasarkan produk kuliner, sehingga mampu 


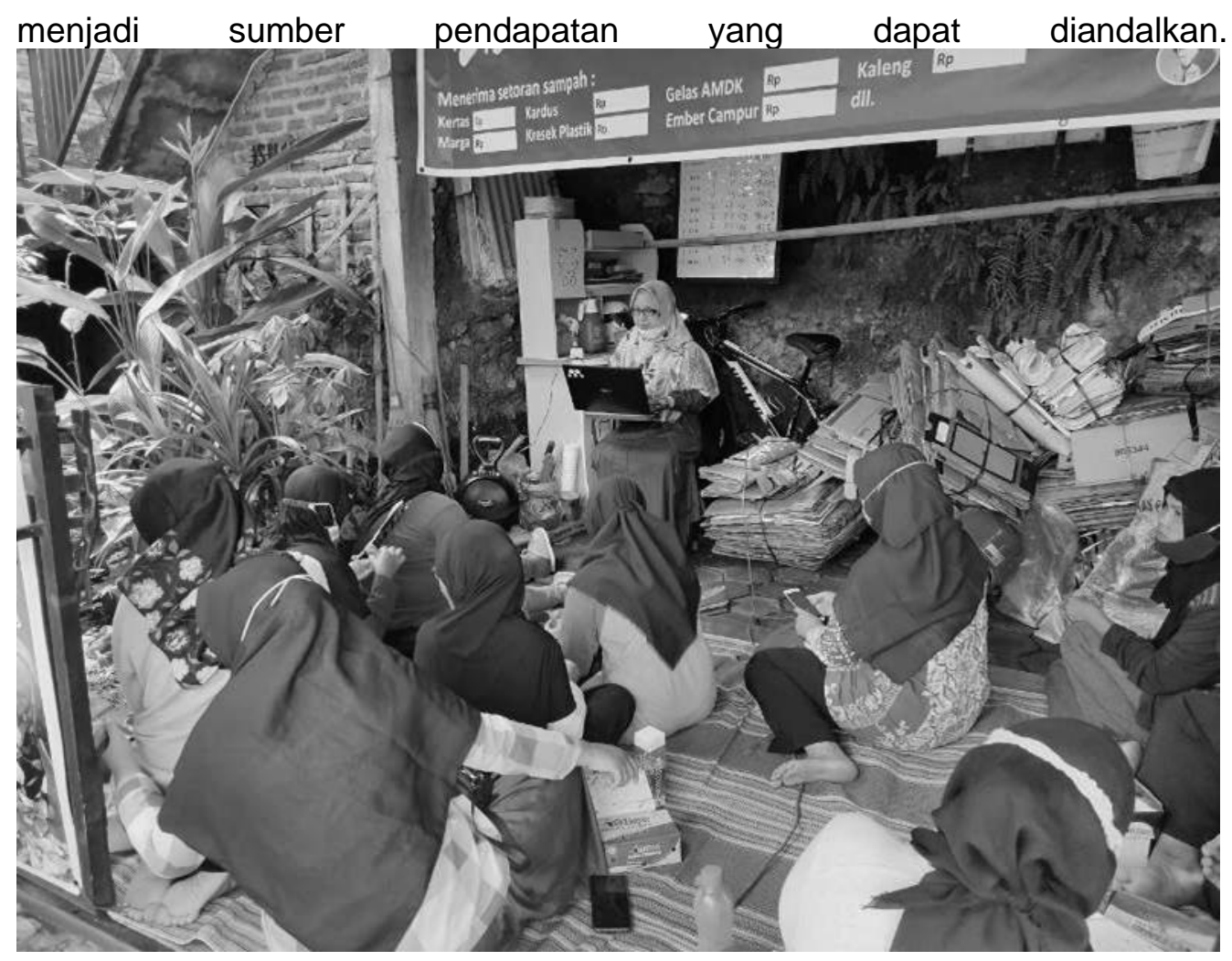

Gambar 1. Penyampaian Materi SAKEMKM

\section{KESIMPULAN}

Dari kegiatan pengabdian kepada masyarakat ini dapat disimpulkan sebagai berikut:

- Permasalahan yang dihadapi Kelompok usaha kuliner antara lain, masalah pengelolaan keuangan bisnis dan pemasaran produk.

- Pada kegiatan ini, para peserta mendapatkan penyuluhan beserta modul mengenai kewirausahaan, pengelolaan bisnis, dan pemasaran terintegrasi.

- Masih ditemukan permasalahan yang dihadapi para pelaku usaha, yaitu permasalahan terkait penyusunan pembukuan sebagai sarana penyedia informasi bisnis. 


\section{DAFTAR PUSTAKA}

Ardaninggar, S. S., Rudy, Sumantri, I. I., \& Nugroho, A. R. (2020). Meningkatkan Profesionalitas Umkm Melalui Tertib Akuntansi Sesuai Sak Emkm Improving. Prosiding Senantias, 1(1), 661-666.

Efriyenty, D. (2021). Pelatihan Membuat Laporan Keuangan Ukm Kube Di Kelurahan Sungai Pelenggut. 3(1), 1-4.

Hidayatulloh, A., \& Maulana, R. (2021). Pelatihan Pembuatan Laporan Keuangan Dan Pajak Pada Usaha Mikro Kecil Dan Menengah Secara Daring. Jurnal Berdaya Mandiri, 3(1), 446-451.

Jaurino. (2021). Evaluasi Laporan Keuangan Berdasarkan Sak - Emkm Pada Pt. Sinar Cahaya Pagi. Equilibrium Manajemen, 7.

Kirowati, D., \& Amir, V. (2019). Implementasi Standar Akuntansi Keuangan Entitas Mikro, Kecil Dan Menengah (Sak Emkm) Pada Laporan Keuangan Di Era Revolusi Industri 4.0 (Studi Kasus Pada Umkm Di Kota Madiun). Jurnal Aksi (Akuntansi Dan Sistem Informasi), 8(5), 55.

Luchindawati, D. S., Nuraina, E., \& Astuti, E. (2021). Analisis Kesiapan Umkm Batik Di Kota Madiun Dalam Penerapan Sak Emkm. Jurnal Krisna, 12(2), 241-249.

Purnomo, A., \& Adyaksana, R. (2021). Meningkatkan Penerapan Sak Emkm Dengan Persepsi Usaha Dan Kesiapan Pelaku Umkm. Journal Of Business And Information Systems (EIssn: 2685-2543), 3(1), 10-22. Https://Doi.Org/10.36067/Jbis.V3i1.90

Purwati, A. S., Suparlinah, I., \& Putri, N. K. (2018). Analisis Pemahaman Literasi Pelaku Umkm Atas Implementasi Standar Akuntansi Keuangan Entitas Mikro, Kecil Dan Menengah (Sak Emkm) Di Kabupaten Banyumas. Prosiding Seminar Nasional Dan Call For Papers, (November), 73-81.

Suwondo, S. (2021). Analisis Penerapan Penyusunan Laporan Keuangan Umkm Berdasarkan Sak Emkm (Studi Kasus Pada Umkm Cv. Nell'q Persada Mandiri). Akunsika: Jurnal Akuntansi Dan Keuangan, 2(1). Https://Doi.Org/10.33884/Jab.V3i2.1219

Wibowo, M. R., Putri, R. F., \& Nasution, R. Y. (2020). Analisis Pencatatan Dan Penyusunan Laporan Keuangan Umkm Berdasarkan Sak Emkm. Seminar Of Social Sciences Engineering \& Humaniora, 342-347. 